Research Article

\title{
Research on Design Optimization of Prefabricated Residential Houses Based on BIM Technology
}

\author{
Nan Liang $(\mathbb{D}$ and Mengxuan Yu \\ School of Architecture and Civil Engineering, Anhui Polytechnic University, Wuhu, Anhui 241000, China \\ Correspondence should be addressed to Nan Liang; liangnan@ahpu.edu.cn
}

Received 18 October 2021; Revised 26 October 2021; Accepted 27 October 2021; Published 9 November 2021

Academic Editor: Rahman Ali

Copyright (C) 2021 Nan Liang and Mengxuan Yu. This is an open access article distributed under the Creative Commons Attribution License, which permits unrestricted use, distribution, and reproduction in any medium, provided the original work is properly cited.

\begin{abstract}
Traditional and conventional methods of architectural and engineering design used for building informational modeling have a number of designs and updating and visualization issues which need to be addressed. In order to improve the design effect of prefabricated residential houses, this study proposes a design optimization method for prefabricated residential houses based on building information modeling (BIM) technology. BIM combines organized, multidisciplinary data to produce a digital representation of an asset across its development, starting from planning and design to building and operations. This study first analyzes the advantages of BIM technology and its applications in architectural design. It is further focused on the design of prefabricated houses, which are based on the optimization theory, modular function, modular design, and modular replacement. These are combined with the monomer architectural form, which is used in prefabricated houses design optimization of the assembly process. Furthermore, the article also focuses on the application of BIM technology in the design optimization of prefabricated residential houses, including the choice of implementation mode, accumulation of experience through the pilot, and the construction of an effective guarantee mechanism.
\end{abstract}

\section{Introduction}

Prefabricated buildings are constructed from prefabricated parts assembled on the job site. Figuratively speaking, prefabricated buildings are similar to "building cars" [1]. The beams, columns, walls, stairs, and balconies that constitute the building are divided into separate designs and then standardized production in the factory into parts, namely, "parts," which are transported to the site to form a stable building through accurate and reasonable "assembly" [2]. At the same time, pipeline separation, integration, and dry construction of the assembly decoration are also major features of the assembly building. Prefabricated buildings can be divided into the prefabricated concrete system, prefabricated steel structure system, and prefabricated wood structure system [3].

China's prefabricated building has been developing for more than 10 years, and now, it has shown a good trend of scale. During the 13th Five-Year Plan period, the average annual growth rate of new prefabricated building areas reached more than 50\%. In 2020, 630 million square meters of prefabricated building area will be started, accounting for 20.5 percent of China's total new construction area that year. It can be said that the development of new building industrialization represented by assembly construction can make up the shortboard of industrialization, automation, mechanization, and intelligence in the field of construction in China and keep up with higher international standards. Continuously advocating the development of prefabricated buildings has important strategic significance for promoting China's development into a construction power. The development of prefabricated buildings conforms to the concept of green development, quality first and efficiency first, and is an important measure to improve quality, quality, and safety in the construction field.

Prefabricated buildings will promote the deeply integrated development of the traditional construction industry and new construction, information, finance, green, building 
materials, environmental protection, and other industries. It will also promote reform and structural adjustment in the construction field, foster new forms of business, drive economic growth, and comprehensively improve the living environment. From the perspective of the future trend, the development of prefabricated buildings should be clearly defined as "measures taken according to local conditions, step by step, active and steady, quality and safety first" development goals and paths. The development of prefabricated buildings should take quality, efficiency, and quality as criteria, establish industrialized and systematic thinking and concept, and attach great importance to engineering quality and safety. We should actively promote the use of project general contracting mode and give full play to the comprehensive advantages. We should adopt a mature, safe, and reliable technology system suitable for this region and build excellent benchmarking demonstration projects. To build green energy conservation and environmental protection of high standards of industrial parks, the application of information technology should be promoted synchronously, and the coordinated development of intelligent construction and building industrialization should be promoted. We should set a benchmark for the industry and build excellent comprehensive demonstration projects.

Different from the traditional brick-by-brick construction, prefabricated buildings move on-site construction to the factory of prefabricated buildings, changing the original construction mode [4]. The walls, floorboards, stairs, and other structural components of characteristic residential buildings were all made in the factory, and workers on the construction site built a lot of residential buildings by building blocks [5]. This can save labor, reduce processes, save time, reduce energy consumption, and reduce pollution, thus promoting the successful transformation and upgrading of the construction industry and supply-side reform.

The planning and design of prefabricated residential buildings is a complex system, and its spatial evolution is characterized by a large number of microactors with initiative and adaptability, as well as the nonlinear interaction between actors and environment, resulting in discontinuous spatial decision-making behaviors of residential buildings. Reference [6] designed a kind of optimization design method based on energy balance calculation, the method based on energy balance in the PHPP software calculation method and calculation formula of the MATLAB platform. Writing optimization calculation programs for building optimization can quickly write a large number of passive energy-saving scheme designs. In [7], an optimization method for prefabricated building design is designed, which illustrates the phenomenon of many assembly unit types and unclean separation in current prefabricated building design in China. Then, based on the design inspiration given by the open building theory and the modulus theory, the method to control the prefabricated building design is analyzed from the horizontal direction and vertical direction. In [8], an optimization algorithm-based optimization design method for residential energy saving is designed. The method takes the
GPSPSOCCHJH algorithm as the optimization foundation, Energy Plus as the simulation engine, and Gen Opt as the operating carrier and builds an energy-saving optimization design process based on the "optimization algorithm." Taking rural residential design as an example for application analysis, the optimal combination of design parameters and energy-saving rate of rural residential with minimum lifecycle cost are obtained.

BIM (building information modeling) is an engineering data model that integrates all kinds of relevant information of construction engineering projects based on 3D digital technology. BIM is the digital expression of the entity and functional characteristics of engineering project facilities [9]. A complete information model can connect the data, process, and resources in different stages of the construction project life and is a complete description of the engineering object, which can be widely used by all the participants of the construction project. BIM has a single engineering data source, which can solve the problem of consistency and global sharing among distributed and heterogeneous engineering data and support the creation, management, and sharing of dynamic engineering information during the life of construction projects [10]. The building information model is also a digital method applied to design, construction, and management. This method supports the integrated management environment of construction engineering, which can significantly improve efficiency and greatly reduce the risk of construction engineering in its whole process. Therefore, based on previous research results, this paper uses BIM technology to design an optimization scheme of prefabricated residential houses.

Key contributions of the use of BIM technology in the design and construction process may include the following:

(1) A cost-efficient solution for the resources management and savings

(2) The project lifecycle reduced by reducing the time taken from the idea's generation to its practical implementation

(3) Improved building quality, better visualization, communications, and coordination

(4) More prospects for prefabrication and modular building

\section{Correlation Analysis of Prefabricated Residential Buildings}

This section introduces the concepts of prefabricated buildings and their association with plaining and other phases of the building information modeling.

2.1. Prefabricated Buildings. Prefabricated building refers to a building that transfers a large amount of on-site work in the traditional construction method to the factory, processes and produces building components and accessories (such as floor slab, wall panel, staircase, balcony, etc.) in the factory, tranships them to the construction site, and assembles and installs them on the site through reliable connection. 
Buildings mainly include prefabricated concrete structure, steel structure, and modern wood structure, which are representatives of modern industrial production mode because of standardized design, factory production, assembly construction, information management, and intelligent application [11].

Prefabricated buildings began to attract interest in the early 20th century and finally came to fruition in the 1960s. Britain, France, the Soviet Union, and other countries first tried these buildings. Prefabricated buildings quickly spread around the world because of their speed and low production costs. The early prefabricated buildings were rigid and uniform in appearance. Later improvements in design added flexibility and variety, allowing prefab buildings to be built not only in batches but in a variety of styles. One type of mobile home in the United States is a relatively advanced prefabricated building. Each residential unit is like a large trailer, which can be used as long as it is pulled to the site by a special car and then lifted by a crane onto the floor pad and connected to the embedded water channel, power supply, and telephone system. The mobile home has heating, bathroom, kitchen, dining room, bedroom, and other facilities inside. Mobile homes can form a single unit or be connected to each other [12].

The prefabricated building is shown in Figure 1.

Prefabricated buildings have the following characteristics:

(1) A large number of building parts are completed by workshop production and processing; the main types of components are outer wall panels, inner wall panels, laminated panels, balconies, air conditioning panels, stairs, precast beams, precast columns, and so on.

(2) A large number of on-site assembly operations, much less than the original cast-in-place operations.

(3) The integration of construction and decoration design and construction; the ideal state is that the decoration can be carried out synchronously with the main construction.

(4) With the standardization of design and informationization of management, the more standard the components are, the higher the production efficiency will be, and the corresponding component cost will decrease. With the digital management of the factory, the cost performance of the whole prefabricated building will be higher and higher.

(5) Meet the requirements of green building.

(6) Energy saving and environmental protection.

\subsection{State-of-the-Art of Refabricated Residential Design and Its}

Planning Development. The design and development of prefabricated residential houses are usually associated with each other. They can contain each other and coordinate with each other, and both play an important role in the development of the city. However, nowadays, the development speed of cities begins to slow down, and there are many

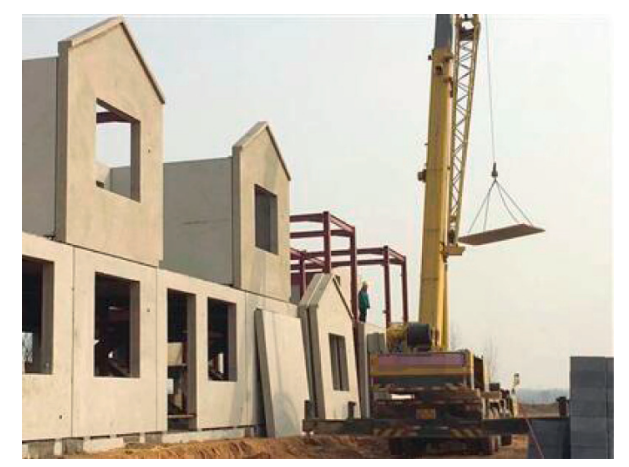

FIgURE 1: Assembly building construction site map.

influencing factors for this situation [13]. First, urban construction in the new era usually requires a lot of manpower and material resources, which requires certain economic support. Some cities with better development can afford the corresponding investment, but for cities with relatively slow development, it is particularly difficult to realize the optimization design and innovation of prefabricated residential houses. Although social and economic development is very important, if the urban residential planning and economic development are combined, the layout of urban land planning can improve the quality of life of urban residents to a certain extent. Secondly, although some cities have the strength to carry out innovative designs for residential buildings, the professional quality of designers is not strong, resulting in unreasonable architectural planning. In general, when planning and constructing prefabricated residential buildings, if the overall consideration is not comprehensive and there is no correlation, it is easy to make the whole planning structure become chaotic and unable to produce certain connections and finally cause the current situation and problems of lack of coordination in urban architectural design.

\section{Relevant Analysis of BIM Technology}

In this section, BIS is introduced, its contributions in the building design are highlighted, and applications are enumerated with a brief description.

3.1. Overview of BIM Technology. BIM technology is an advanced CAD technology based on architectural design objects. It digitally describes buildings and integrates all building information in a virtual model, which is a major change in the development of the construction industry [14]. As for civil building design, the virtual model based on BIM technology integrates all building information or building components, such as material properties and physical characteristics, as shown in Figure 2.

In addition to being used for architectural design, it can also be used for cost analysis, equipment management, structural design, etc., which plays an important role in the whole life cycle of the building.

In fact, CAD is not a new concept, and the digital description of buildings has always been an ideal state, but it 


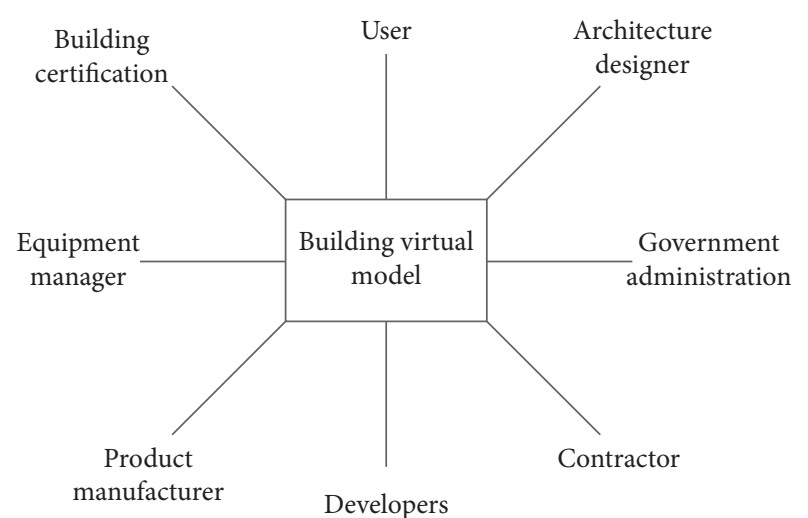

FIgURE 2: Use BIM technology to integrate building model information.

has not been commercialized. However, with the popularity of personal computers, application systems based on BIM technology have been developed. Based on BIM technology drawing software to break the limitations of low-level drawing tools, the operating object is changed from the original point, line, and plane geometry to the door, window, and wall body three-dimensional construction; the computer is no longer used to modify some unrelated points and lines, but this is done by some architectural component of the overall operation [15].

Taking "window" as an example, the comparison results of the window model built by traditional drawing tools and BIM software are shown in Figure 3.

In recent years, some famous CAD software developers all over the world have launched and continuously improve their BIM software. Although the name of BIM technology is not exactly the same, the characteristics of the building model constructed by BIM software can be roughly summarized as the following three points:

(1) Composition of building components with defined parameters and in dynamic parallel connection

(2) Real-time 2D, 3D, and virtual model display and adjustment

(3) Fully integrated nongraphical data reporting form

3.2. Advantages of BIM Technology in Residential Design. For the traditional two-dimensional CAD drawing work, engineering designers waste more time in drawing drawings, making charts, and other aspects, often ignore the importance of the design link, and communicate with other designers, builders, customers, and other difficulties. In this regard, the residence design based on BIM technology will liberate designers from tedious drawing work. As long as the simulation building model is established, relevant architectural documents, architectural drawings, architectural charts, and so on can be automatically generated in each design link. At the same time, the construction of a threedimensional building model also allows engineering designers to communicate freely with others. Generally speaking, the biggest advantage of BIM-based architectural design simulation is that it can not only effectively use the efficient intelligence of computers to ensure the quality of architectural design but also improve the accuracy of drawings and avoid rework, which greatly improves the efficiency of architectural design [16].

Figure 4 shows the schematic diagram of the comparative analysis of the workload of traditional two-dimensional CAD drawing design and BIM-based simulated architectural design.

It can be seen from Figure 4 that traditional 2D CAD drawing design takes more time in the drawing process but less time in professional design. However, in BIM technology based on the simulation of building design through the simulation of building in the design of more time, some drawings and charts are automatically generated. It can be seen that, for the same civil building design, the time and design quality of BIM-based simulation building design are far better than those of two-dimensional CAD drawing design.

In a word, the advantages of BIM-based simulation architectural design are generally reflected in the following points:

(1) Architectural simulation design

(2) Automatically generating drawings, charts, etc.

(3) Updating design information dynamically in real time

(4) Advanced analytical skills

\subsection{Common Application of BIM Technology in Residential Construction}

3.3.1. Simulation and Comparison Optimization. The application of BIM technology in residential design is based on the integration of the material properties, design characteristics, physical characteristics, and other information of residential buildings with BIM model, to simulate and calculate the lighting, noise, ventilation, water supply, energy consumption, and other information of residential buildings, so as to provide the data analysis results of optimal design for architectural designers, such as selecting building equipment that reduces energy consumption by combining cooling and heating needs and assessing a building's carbon footprint with local climate and statistics.

3.3.2. The Data Source Is Unique and the Information Is Dynamically Correlated. BIM technology gathers building engineering information into a unified database, and the relevant design content is stored in a dynamically related model file, that is, the architectural design information database. Whether it is a 3D model, plane drawing, or statistical data, etc., simulation models are dynamically generated and associated with each other dynamically, realizing real-time dynamic updates. In fact, the building model information in each stage of a construction cycle is the same, and it does not need to be recorded repeatedly. It can be supplemented by relevant designers according to the 


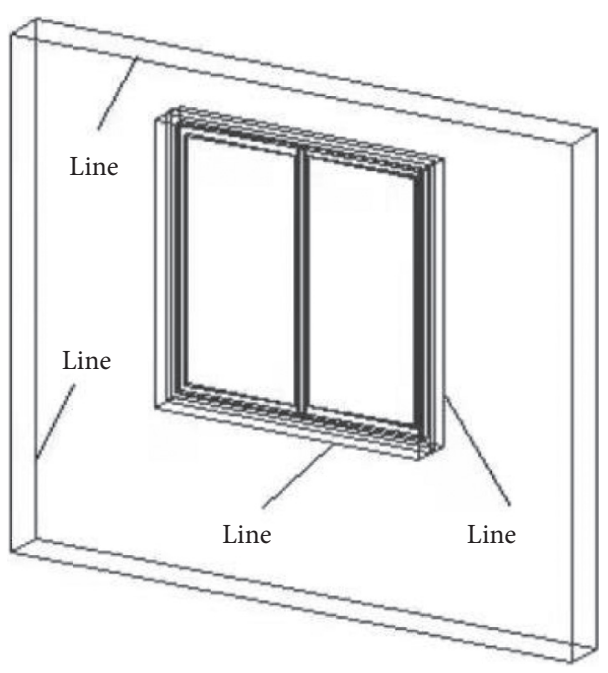

(a)

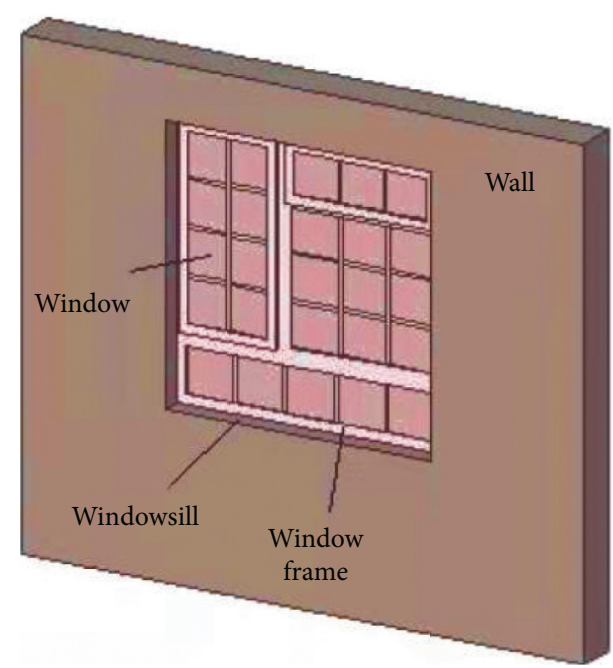

(b)

FIGURE 3: Comparison between traditional drawing tools and BIM software for building object models. (a) Window models in traditional drawing tools. (b) Window model in BIM software.

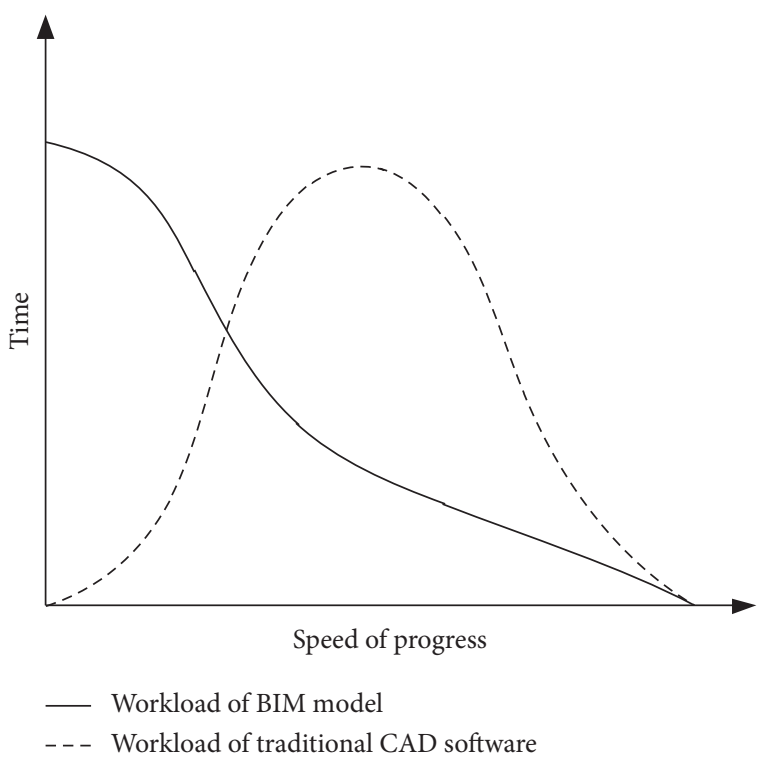

FIGURE 4: Comparison of workload to be processed between the traditional CAD drawing and BIM model.

purpose, which fundamentally solves the problem of disunity of information.

\subsubsection{Unified Standards Improve the Efficiency of Architectural} Design. The so-called unification of design standards refers to the collection of relevant design criteria and design methods into the TEMPLATE database of the BIM model, in which all design professionals can query and update the design information, so as to realize the unity of design. After long-term updating and replenishment, the BIM model database forms design templates such as size and style, which, in terms of long-term development, greatly improves the work efficiency of designers.
3.3.4. Professional Design Visualization and Collaboration. In fact, BIM technology provides basic support for professional design visualization and collaboration. For example, to establish a professional BIM design team, the basic core documents are set up by architecture professionals, and each design professional sets up local documents on the basis of the core documents with the help of relevant software and carries out design work in their local files. In addition, BIM technology based on building, architecture, and equipment as one of the three-dimensional building models to achieve the visualization and sharing of professional information, without relying on human intervention, truly achieves the collaborative design.

3.3.5. Strengthening the Quality of Architectural Design and Reducing Rework. As for the collision problem of architectural design, the traditional detection method is that the engineering designer overlaps each plane and combines the sectional view to detect the collision. However, the detection method based on BIM technology is to use the computer to detect the collision problem in real time, which improves the accuracy. Generally speaking, after the BIM model is built, Navisworks software will be used to detect the collision problems between various professions, and the design will be improved according to the data analysis results, so as to effectively solve the collision problems.

3.3.6. Combined with Customer Requirements and Architectural Simulation. Under normal circumstances, architectural designers should constantly ask the specific needs of customers in the design stage, so as to constantly adjust the design scheme during the design and select the right model to fully display the architectural results, so that customers can understand the effect of the completion of the building. Although BIM technology has certain advantages in the 
application of civil architecture design, its standards for hardware and software are also high.

\subsection{Innovative Application of BIM Technology in Residential Construction}

(1) Use BIM to simulate construction, timely correct construction design mistakes, and combine with VR technology to realize visual simulation construction. The previous flat components into a three-dimensional simulation graphics and videos and $3 \mathrm{D}$ renderings can be seen in advance, and even the applicability and safety of prefabricated residential houses can be simulated.

(2) Use BIM technology to build models, and use BIM model detection tools to find conflicts between elements in residential buildings and timely improve and adjust; the existing conditions, construction sequence, and key and difficult solutions of the residential construction site are demonstrated in advance through video; an environment-friendly residential model is obtained through computer analysis.

(3) BIM joint RFID information sharing platform will use the size of the component in the process of residential construction, installation position, and other information into RFID chips and thus, for the member management, improve the efficiency of the residential project site information extraction, realtime control component in the process of design, production, transportation, and construction information, and realize the whole process of information sharing and collaborative work. The BIM information platform associated with computer equipment can guide the assembly of components on site, improve the efficiency of site construction, and ensure the quality of project construction.

\section{Design Optimization of Assembled Residential Houses Based on BIM Technology}

Based on the above analysis, this study takes a certain area as an example to optimize the design of prefabricated residential buildings in this area by using BIM technology. This region is located in the subtropical monsoon climate zone; the four seasons are obvious, adequate light, abundant rain, hot summer, and cold winter. The buildings in this area are usually narrow in width and deep in depth. The central axis of the courtyard is the passage, which has the structural advantages of waterproof, fire prevention, warm and cold prevention, ventilation, lighting, drainage, and so on. It has important reference value for the architectural design of contemporary new residential buildings.

\subsection{Theoretical Basis of Design Optimization of Prefabricated} Residential Houses. Studying relevant materials at home and abroad, foreign prefabricated construction has a specification, policy, design, production, sales, transportation, construction, information, finance, and so on; a series of complete industrialized building industry chain, component, and part of the residence and a high degree of standardization, generalization, and commercialization, for users' personalized prefabricated building assembled laid a foundation.

In terms of the design of prefabricated residential buildings, modular standard system, module splicing and combination, and structure selection of foreign small residential buildings have a great influence on China. It is a good idea to optimize the design of prefabricated residential buildings by referring to the design ideas of foreign small residential buildings.

4.1.1. Modularization. Modularization is the foundation of the development of prefabricated buildings and the basis of realizing the standardized production of components. Some countries in the United States, Japan, and Europe emphasize standardized design very much. There are not only many specialized institutions for studying standardization but also universal production and manufacturing of parts such as building structure, mechanical and electrical equipment, pipes, and home decoration.

The premise of modularization is to realize the unity of elements, and the user's living habits, hobby needs, and residential ring are the basis for the derivation of modular prefabricated residential buildings. Modular need comprehensive consideration of function, according to the different requirements of users, can deduce the corresponding function, such as drying, food storage, small shops, and raising small animals, to human body engineering, the crowd again considering the manufacture, processing, packing, transportation, hoisting, construction size, the size of the regular doors and windows, furniture, and other construction decoration factors, and finally determine the plane size and module value required by the function.

4.1.2. Modular. The concept of "modular design" was first applied in the process of machine tool design, until the 1850s, where some countries in Europe and the United States formally put forward the definition of "modular design." The main characteristics of modular design are serialization, combination, generalization, and standardization. The broad sense of modularity refers to the combination of various module parts to form different products and meet different needs, which is consistent with the goal of the assembly building.

Prefabricated houses design optimization to consider the function, component, space, decoration, and other factors; accordingly, the design of the object is different and can be divided into modular adjusted functional modules (bedroom, dining room, kitchen, toilet, etc.), composed of the main structure of the building component module (column, beam, wall, floor, stair), the adornment of the facade module (parapet, roof), and built-in module (integral bathroom, integral kitchen). The combination of these modules can simplify the scheme design to the construction design, and the mutual substitution of 
modules can realize the diversified personalized expression of residential houses.

4.1.3. Selection of the Structure. Some developed countries in the United States, Japan, and Europe have gradually developed a set of assembly-type small housing systems adapted to their national conditions in long-term exploration. For example, Japan is dominated by wood structure housing, the United States is dominated by wood structure and light steel structure system, and Germany is dominated by light steel structure system. In general, light steel structure and wood structure have the advantages of high production efficiency, high degree of industrialization, fast assembly speed, low transportation cost, high room comfort, good earthquake resistance, relatively independent structure, and interior decoration in the field of small housing and occupy a leading advantage in a foreign assembled small housing. Therefore, in the design optimization of prefabricated residential houses, we can learn from the small residential system of developed countries in Europe and America to establish a set of assembly systems adapted to local conditions.

\subsection{Design Optimization Idea of Assembled Residential Houses} Based on BIM Technology. Through the relevant data modules collected in the preliminary investigation, the functional modules are combined on the basis of modularization, and the spatial forms of residential houses are diversified and spliced. It is hoped that through this design idea, the limited functional modules can derive rich architectural forms and meet the personalized needs of different users.

4.2.1. The Early Stage of the Research. Through data search, household interview, and other forms, the family population composition, economic income, living habits, and users' demand of the construction area were counted. It is found that the functional requirements of the residents in this area include not only living space (living room, master bedroom, secondary bedroom), auxiliary space (dining room, study, kitchen, bathroom, living room, balcony), and transportation space (porch, stairwell) but also additional space (storage room, processing room, shops, garage). There is little difference in users' demand for living space, traffic space, and auxiliary space in the area of the toilet, but there is a certain difference in the area demand for dining room, kitchen, living room, and additional space.

4.2.2. Modular Function Modules. By means of light steel structure and comprehensive comparison of PC structure, the average price is quite better, light steel structure is better than the PC structure, and transportation advantages have assembled the user mode transformation of life and future family demand changes of architectural function and spatial variability that put forward certain requirements, such as two curtilage combined into one, the second partition of large space, and function layout adjustment. Steel structure and light filled wall have the advantage of flexibility and being more easy to adapt to the rapid development of family changes. Therefore, light steel structure is selected in this design, and the common thickness of composite wall is $300 \mathrm{~mm}$ and $150 \mathrm{~mm}$.

In order to facilitate assembly construction, the building adopts a townhouse-like form, combining the two houses and extracting the required functional modules, including living space (master bedroom), auxiliary space (study, living room, toilet, balcony), transportation space (stairwell), and additional space (storage room). The functional modules of prefabricated dwellings are shown in Figure 5.

Through the analysis, it is found that the bedroom, kitchen, study, and balcony are the most economical to set in $3000 \mathrm{~mm}$, the functional modules of the kitchen, study, and balcony are unified in $3900 \mathrm{~mm} \times 3000 \mathrm{~mm}$ plane, and the floor height is $3000 \mathrm{~mm}$. Each functional module is coordinated and convenient for construction.

4.2.3. Combination of Function Modules. Common plane combinations of functional modules are centralized, courtyard, and series. Centralized combination refers to the combination of each unit module of different sizes into a relatively regular plane form, which is common in intensive small residential design. Courtyard combination refers to the combination of unit modules into a plane form similar to the traditional courtyard form. Tandem combination refers to the connection of various modules through narrow traffic modules, shaped like fish bones.

Due to the limited area of the residential base, this design adopts a centralized combination method. In the functional module, the partition position on the third floor is reserved to reserve enough variable space for the change of family needs in the future.

The overall structure of the module is shown in Figure 6.

4.2.4. Module to Replace. Module replacement can recombine functions, spaces, parts, and components in accordance with the same regulations and give full play to the combined advantages of assembly building similar to "building blocks", from design to construction, from the plane to the facade to achieve free combination, to meet the needs of users, to achieve the diversity of house design, and to fully realize the customization of the assembled folk houses.

4.2.5. Single Building Form Expansion. A module is decomposed into two functional integration modules that mirror each other, and more possible architectural forms can be quickly deduced through multidirection integration. Theoretically speaking, the two modules can be connected in series, parallel, superposition, dislocation, overlap, connection, diagonal, intersection for vertical or horizontal splicing combination, and the use of rotation and mirror adjustment. In this case, after comprehensive consideration of lighting, ventilation, traffic, and modeling, the combination of dislocation, parallel, diagonal, and flip is selected to expand from a prototype to a variety of different forms of architectural units, and the newly generated architectural units can also be replaced by modules to achieve colorful architectural personalized expression. 


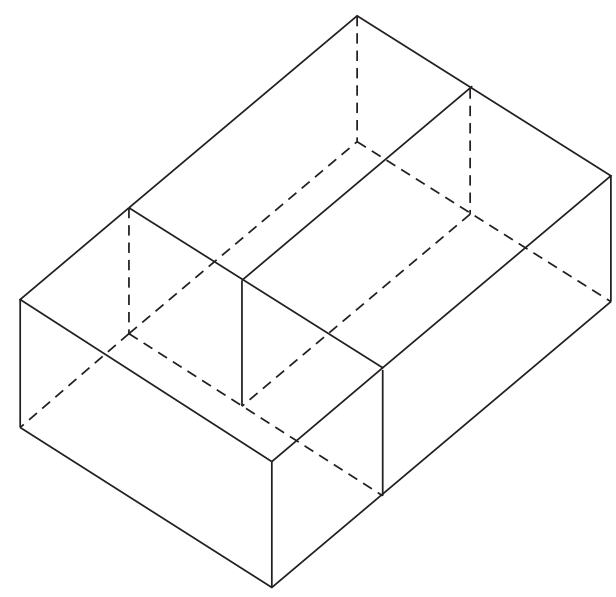

Figure 5: Assembly-type folk house function module planning thought diagram.

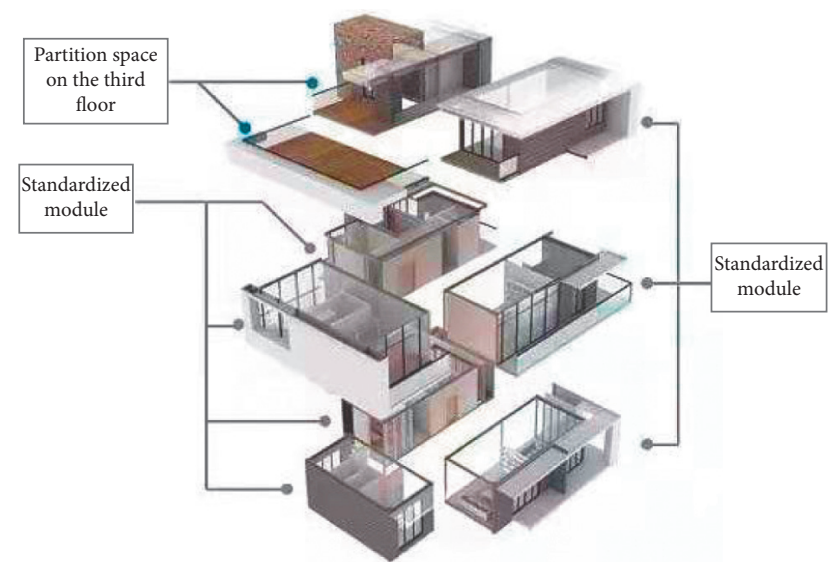

FIgURE 6: Modular structure composition of prefabricated residential houses.

4.3. Module Model In-Depth Design and Preassembly. On the basis of the above optimization design ideas, it is necessary to split the continuous BIM model components into independent prefabricated components that can be produced by the factory and complete the reinforcement design of the prefabricated components and the structural design of the directly connected nodes of the prefabricated components.

The use of BIM technology to deepen the design of prefabricated not only can clearly convey the traditional relationship between $2 \mathrm{D}$ drawings but can also directly express the component reinforcement of spatial relations, node structure, and parameters of various modules and automatically generate artifacts blanking sheet, work order, and mold specifications, such as production form, implementation, and prefabricated factory close synergy and docking.

After the component splitting principle is established for the assembled residential structure model, BIM technology can be used to call Dynamo for visual programming, split the cast-in-place components into parts, and then combine each part to form components to complete the structural splitting.
4.4. Collision Check. As the project is an assembly-type residential building, holes should be accurately reserved for a large number of components such as floor slab, beam, and column. First of all, BIM technology should be used to coordinate and blend all modules to check errors, leaks, and defects, save time, and improve efficiency. Secondly, the site installation of prefabricated components puts forward high requirements for in-depth design. Therefore, the in-depth BIM model is imported into Navisworks software for intelligent collision inspection of each node to avoid the contradiction between design, component production, and site construction. Finally, all module models are imported into Navisworks software for further detection, so as to completely solve the pipeline and civil engineering collision and other problems.

4.5. Construction Process Simulation. In this study, the BIM 5D software of Glodon is used in the simulation of construction progress. First, the project management software Microsoft Project is used to make the construction schedule, and then, it is imported into the BIM information model. Time and resource dimensions are introduced into the $3 \mathrm{D}$ model, and the 3D-BIM model is transformed into the 5DBIM model, as shown in Figure 7.

The 5D-BIM model is used to simulate the whole construction process and the allocation of various resources and intuitively present the information of schedule arrangement, construction technology, and capital investment status. At the same time, the simulation results can be used to compare the actual progress with the planned progress, so as to repeatedly consider the rationality of the construction control method and construction arrangement and the correctness of the working procedure and timely optimization, to avoid the construction schedule delay and cost increase caused by careless consideration. The use of 5D-BIM for construction simulation can also assist the technical workers of the construction unit to understand the assembly composition and construction process of the whole prefabricated building in detail, improve the actual operation efficiency, and realize the dynamic management of the construction schedule and cost by the management personnel, so as to ensure the project on schedule.

To sum up, the design optimization of prefabricated residential houses has been completed to meet the use requirements of different users through module block and module replacement. On this basis, the assembly holes of external stairs and terraces are reserved outside the building, so that the external space of the building can be effectively utilized. Finally, the model structure of prefabricated residential houses is shown in Figure 8.

\section{BIM Technology in the Design Optimization of Prefabricated Residential Houses}

This section explains the selection of implementation mode, accumulation of experience, and effectiveness. 

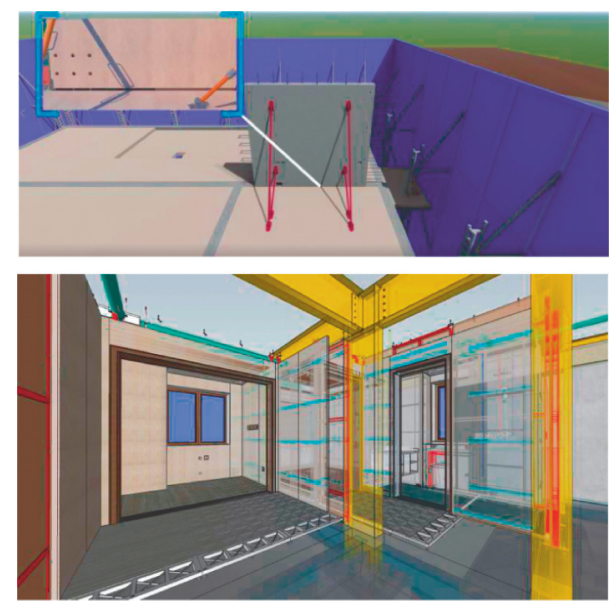

FIGURE 7: 5D-BIM construction simulation renderings.

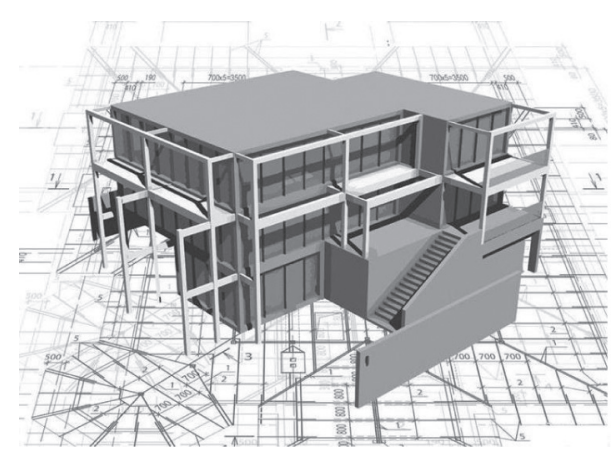

FIGURE 8: Model structure of prefabricated residential houses.

5.1. Selection of Implementation Mode. In terms of enterprises applying BIM technology in China, there are generally two implementation modes: first, the parallel mode of the design team and BIM team, that is, the professional design team does not change, and another BIM team is set up to build BIM building model; second, design and BIM integration model, that is, designers build BIM building model by themselves. The advantages of the first mode are easy to promote, low risk, and good quality; the disadvantage is to produce extra personnel costs. The priority of the second mode is to maximize the advantages of BIM technology and ensure design efficiency. However, it has high requirements on the quality of designers.

In view of the application of BIM technology in general civil construction enterprises, a parallel mode can be adopted in the initial stage of construction; that is, an independent BIM team can be set up in combination with factors such as the difficulty of design and application, the quality level of designers, and the risk of engineering. With the mature application of BIM technology, it can be gradually transformed into an integrated mode.

5.2. Accumulating Experience through Pilot. Compared with the traditional two-dimensional CAD drawing design, there are great changes in the design mode and design process of the virtual model based on BIM technology. Therefore, BIM technology should not be comprehensively applied in the early stage but should accumulate experience in the pilot project and then gradually promote. For the selection of pilot projects, it is best to have completed or basically completed construction projects, without the risk of delay, and at the same time, it should cover all professions, ensure that all kinds of engineering personnel can participate in BIM design, and dig out the person in charge of BIM technology application, to lay a foundation for the subsequent promotion. In the application of BIM technology in pilot projects, common problems in the application process of BIM technology should be summarized, and a preliminary construction, management, and application standard system should be established to provide effective opinion analysis for the further promotion of BIM technology.

5.3. Building an Effective Guarantee Mechanism. At present, the production process management of the AEC industry in China is mostly based on two-dimensional drawings. With the wide application of BIM technology, in order to ensure the effectiveness of $3 \mathrm{D}$ design, it is urgent to solve the problems of construction and 3D design archive and to build an effective guarantee mechanism.

\section{Conclusion}

In order to optimize the design of prefabricated residential houses, this study designed a design optimization method of prefabricated residential houses based on BIM technology. The advantages and application forms of BIM technology are improved and analyzed. Based on the optimization theory of prefabricated residential houses, modular functional modules, the combination of functional modules, and module replacement are designed to meet the user needs of prefabricated residential houses, in order to provide theoretical support for the development and application of prefabricated residential houses.

In the future, we are planning to involve BIM in almost all stages of buildings' design to improve the processes of collaboration and communication.

\section{Data Availability}

The data used to support the findings of this study are available from the corresponding author upon request.

\section{Conflicts of Interest}

The authors declare that they have no conflicts of interest.

\section{Acknowledgments}

The authors would like to acknowledge the Key Research Project Fund of Humanities and Social Sciences in Anhui Universities: Expression of Traditional Design Vocabulary Based on Prefabricated Houses in Southern Anhui under the Background of Rural Revitalization, no. SK2020A0232. 


\section{References}

[1] Y. Cui, S. Li, C. Liu, and N. Sun, "Creation and diversified applications of plane module libraries for prefabricated houses based on BIM," Sustainability, vol. 12, no. 2, pp. 156-168, 2020.

[2] S. Yang, "Construction of video courses of physical education and health education in colleges and Universities under the MOOC platform," Mobile Information Systems, vol. 2021, Article ID 9925838, 8 pages, 2021.

[3] X. Du, "Research on engineering project management method based on BIM technology," Scientific Programming, vol. 2021, Article ID 7230585, 10 pages, 2021.

[4] A. Hollberg, G. Genova, and G. Habert, "Evaluation of BIMbased LCA results for building design[J]," Automation in Construction, vol. 109, no. 1, pp. 1-9, 2020.

[5] J. P. Carvalho, L. Bragana, and R. Mateus, "Sustainable building design: analysing the feasibility of BIM platforms to support practical building sustainability assessment," Computers in Industry, vol. 127, pp. 103-120, 2021.

[6] M. Chen, C. Gao, Z. Yu, and J. Wang, "Optimal design method of passive house based on energy balance calculation," Building Science, vol. 36, no. 10, pp. 62-67, 2020.

[7] M. A. Li, D. Zhou, and J. Jia, "Optimization of prefabricated building design for scientific research building of school of human settlements, xi 'an jiaotong university," Industrial Construction, vol. 49, no. 4, pp. 200-205+179, 2019.

[8] T. Shao and H. Jin, "Optimization design of energy saving for rural houses in severe cold regions based on an optimization algorithm," Building Science, vol. 35, no. 12, pp. 99-107, 2019.

[9] G. Demirden, N. Sena Diren, H. Alada, and I. Zeynep, "Lean based maturity framework integrating value, BIM and big data analytics: evidence from AEC industry," Sustainability, vol. 13, no. 1, pp. 365-374, 2021.

[10] B. Wang, "Optimization design of BIM system for construction building process in virtual reality," Modern Electronics Technique, vol. 43, no. 10, pp. 160-162, 2020.

[11] Q. He, C. C. Scienceamp, and T. Co, "Investigation on BIMbased integration mode of building Design,Construction and operation," Construction Science and Technology, vol. 21, no. 6, pp. 48-55, 2019.

[12] W. Chen, X. Sun, R. Chen, and L. I. Hui, "Design, management and control optimization of prefabricated components of prefabricated buildings based on QFD-DSM," Journal of Civil Engineering and Management, vol. 37, no. 4, pp. 39-45, 2020.

[13] S. G. Mahiwal, M. K. Bhoi, and N. Bhatt, "Evaluation of energy use intensity (EUI) and energy cost of commercial building in India using BIM technology," Asian Journal of Civil Engineering, vol. 22, no. 3, pp. 1-18, 2021.

[14] W. Yan, Y. Zhang, W. Zhang, M. Ji, and T. Wang, "Study on optimization of folded reticulated shell house based on windresistant design," Building Structure, vol. 49, no. 11, pp. 128-134, 2019.

[15] U. Vitiello, V. Ciotta, A. Salzano, D. Asprone, G. Manfredi, and E. Cosenza, "BIM-based approach for the cost-optimization of seismic retrofit strategies on existing buildings," Automation in Construction, vol. 98, no. 2, pp. 90-101, 2019.

[16] M. M. Farid, "Integration of building energy modeling (BEM) and building information modeling (BIM): workflows and case study," Building Technology Educator's Society, vol. 19, no. 1, pp. 37-49, 2019. 